\title{
Complementary and alternative medicine: A pilot survey of current clinical practice and attitudes of physiotherapists in the Otago region of New Zealand
}

\author{
Lizhou Liu PhD \\ Lecturer, Centre for Health, Activity and Rehabilitation Research, School of Physiotherapy, University of Otago, Dunedin, \\ New Zealand
}

\section{Julia Tarbotton BPhty}

Centre for Health, Activity and Rehabilitation Research, School of Physiotherapy, University of Otago, Dunedin, New Zealand

Krista Martin BPhty

Centre for Health, Activity and Rehabilitation Research, School of Physiotherapy, University of Otago, Dunedin, New Zealand

Taylor Haenga BPhty

Centre for Health, Activity and Rehabilitation Research, School of Physiotherapy, University of Otago, Dunedin, New Zealand

Sam Wu BPhty

Centre for Health, Activity and Rehabilitation Research, School of Physiotherapy, University of Otago, Dunedin, New Zealand

G. David Baxter TC, BSC(Hons), DPhil, MBA, FCSP

Professor, Centre for Health, Activity and Rehabilitation Research, School of Physiotherapy, University of Otago, Dunedin, New Zealand

\section{ABSTRACT}

This pilot survey aimed to explore the feasibility of conducting a nationwide survey investigating the current practice and attitudes towards complementary and alternative medicine (CAM) in New Zealand registered physiotherapists. This was a cross-sectional, online study using a questionnaire developed from previous survey instruments. An electronic link to the questionnaire was distributed via email to members of the Otago Branch of Physiotherapy New Zealand $(n=344)$. Questions included current clinical practice and use of CAM as well as attitudes and opinions on its effectiveness. Feasibility outcomes of this survey included the response rate and completion rate. Data were analysed in Microsoft Excel®. The response rate was $10.5 \%(n=36)$ and the completion rate was $86.1 \%(n=31 / 36)$. A range of conditions treated with CAM were cited by respondents; the most frequently treated condition was "back and neck pain" $(n=10 / 36)$. Physiotherapists in this sample believed acupuncture and massage are the most effective CAM modalities used for "back and neck pain" treatment and were most likely to use acupuncture and massage as CAM modalities when treating these conditions. Acupuncture was found to be the most common CAM practiced by respondents, and an acupuncturist was the CAM practitioner to which patients are most commonly referred by respondents. This study demonstrated that conducting a nationwide survey is feasible, subject to an improved survey design and increased response rate. Such a survey is scheduled in 2021 in order to gather a more representative understanding of the practice and attitudes towards CAM among New Zealand physiotherapists.

\section{Liu, L., Tarbotton, J., Martin, K., Haenga, T. \& Baxter, G. D. (2020). Complementary and alternative medicine: A pilot survey of current clinical practice and attitudes of physiotherapists in the Otago region of New Zealand. New Zealand Journal of Physiotherapy, 48(3), 127-137. https://doi.org/10.15619/NZJP/48.3.04}

Key Words: Complementary and Alternative Medicine, Physiotherapy, New Zealand, Back and Neck Pain, Acupuncture

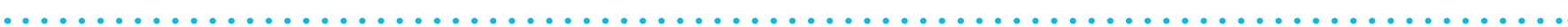

\section{INTRODUCTION}

Complementary and alternative medicine (CAM) is a group of healthcare systems, practices, and products that are not considered part of conventional medicine (Adams et al., 2012). CAM modalities are divided into five main categories by the National Center for Complementary and Alternative Medicine in the United States: alternative medical systems, biologically based treatments, manipulative and body-based methods, mind-body interventions, and energy therapies (National Center for Complementary and Alternative Medicine, 2000) (Table 1). CAM therapies follow a holistic model of health, employing interventions that promote the innate healing ability of the body while retaining a core focus on individuality, holism, education, and disease prevention (Leach, 2010). The growing use of CAM worldwide (Abuelgasim et al., 2018; Asfaw Erku \& Basazn Mekuria, 2016; Frass et al., 2012; Teo et al., 2016; Wode et al., 2019) can be attributed to many factors. These include but are not limited to the move towards holistic well-being, the recognition of the limitations associated with conventional medicine, and the increasing discourse on the important contribution of CAM to overall health and wellbeing (Stratton \& McGivern-Snofsky, 2008). There is limited research 
Table 1

Categories of CAM Therapies (National Center for Complementary and Alternative Medicine, 2000)

\begin{tabular}{lllll}
\hline $\begin{array}{l}\text { Alternative medical } \\
\text { systems }\end{array}$ & $\begin{array}{l}\text { Mind-body } \\
\text { interventions }\end{array}$ & $\begin{array}{l}\text { Biologically based } \\
\text { interventions }\end{array}$ & $\begin{array}{l}\text { Manipulative and } \\
\text { body-based methods }\end{array}$ & $\begin{array}{l}\text { Energy therapies } \\
\text { Ayurveda }\end{array}$ \\
Homeopathy & Art therapy & Biological therapies & Chiropracty & Magnets \\
Naturopathy & Dance & Herbal therapies & Massage & Qigong \\
$\begin{array}{l}\text { Traditional oriental medicine } \\
\text { (acupuncture) }\end{array}$ & $\begin{array}{l}\text { Hypnosis } \\
\text { Meditation }\end{array}$ & $\begin{array}{l}\text { Orthomolecular therapies } \\
\text { Special dietary therapies }\end{array}$ & Osteopathy & Reiki \\
& Music & & & Therapeutic touch \\
& Prayer & & & \\
\hline
\end{tabular}

in New Zealand on CAM. The most recent nationwide survey providing information on the use of CAM showed that $25 \%$ of New Zealanders visited a CAM practitioner during a 12-month period (Ministry of Health, 2004). Another two regional surveys reported that CAM had been used by $38 \%$ of people presenting to an emergency department (Nicholson, 2006) and 49\% of cancer patients in a cancer treatment centre (Chrystal et al., 2003). CAM users are more likely to be middle-aged, female, educated, and European (Nicholson, 2006; Pledger et al., 2010).

The boundary between CAM and conventional therapy is vague and continually shifting, as it largely depends on cultural and political attitudes (Dew, 2003). A nationwide survey evaluating the views and use of CAM by general practitioners (GPs) in New Zealand showed GPs had different viewpoints on whether therapies were considered conventional or CAM (Poynton et al., 2006). The study found that approximately $20 \%$ of GPs practice CAM, of whom $95 \%$ refer patients to one or more forms of CAM. While the most common CAM therapy practiced by GPs was acupuncture, chiropractic manipulation was the most common GP-referred CAM therapy. Of the responding GPs, $32 \%$ had formal training in one or more CAM therapies and $29 \%$ were self-educated. It reported that GPs wanted more CAM education as part of their medical education.

Physiotherapy is one of the allied health professions that aims to remediate impairments, and promote mobility and function. In New Zealand, physiotherapists provide a range of therapeutic techniques including advice, exercises, and mobilisation (Physiotherapy Board of New Zealand, 2020). Meanwhile, physiotherapists practice some techniques that could be considered CAM therapies, for example acupuncture, which is offered at a postgraduate level and considered within the general scope of physiotherapy practice by New Zealand's physiotherapy regulatory body (Physiotherapy Board of New Zealand, 2008). However, there have been no studies to date to evaluate New Zealand physiotherapists' level of use of CAM and perceptions toward CAM in routine practice. Prior to undertaking a nationwide survey to investigate the current clinical practice of CAM, and the knowledge and attitudes of CAM among New Zealand physiotherapists, a pilot survey was carried out as an essential precursor. This pilot survey aimed to investigate:

1. The feasibility to conduct a nationwide survey using the current survey design.
2. The current practice and attitudes towards CAM in physiotherapists in the Otago region of New Zealand.

\section{METHODS}

Data collection: Overview

This was a pilot online questionnaire survey of physiotherapist members of the Otago Branch of Physiotherapy New Zealand (PNZ), of which there were 344 registered members (Physiotherapy New Zealand, 2018). Ethical approval for this study was obtained from the University of Otago Human Ethics Committee (Health) (reference number 18/117), and Māori consultation was completed through the Ngāi Tahu Research Consultation Committee.

The questionnaire was designed to investigate the views and use of CAM by physiotherapists. It was based on questionnaires exploring the perception and use of CAM by physiotherapists in the United Kingdom, which have demonstrated excellent validity and response rates (Hughes et al., 2011; Osborn, 2001; Quinn, 2006). The content was tailored to the New Zealand context based on feedback from experienced researchers and physiotherapists ( $n=5$ ) working at the Centre for Health, Activity and Rehabilitation Research, School of Physiotherapy, University of Otago. Content and face validity of the survey were investigated by piloting the survey among a group of physiotherapists ( $n=5$ ) currently working at the School of Physiotherapy clinics (Dunedin). The physiotherapists were asked to evaluate the questionnaire contents against the goal of this study, as well as the flow and logic of survey items, after which suggested (minor) amendments were incorporated. A biostatistician reviewed the final questionnaire for face validity before it was converted into Qualtrics ${ }^{\circledR}$, an online survey tool which was used to conduct this study.

The invitation and links to the questionnaire, and the participant information sheet were sent by the administrator of PNZ via email to all physiotherapists within the Otago Branch. Participants had 13 days to complete the survey based on the timeframe for the study, which was completed as part of a 6-week research paper for final-year University of Otago physiotherapy students. One reminder email was sent 5 days after the initial release. All participants consented to participate in the survey.

\section{Questionnaire}

The questionnaire contained three sections (Appendix A). Section 1 sought physiotherapists' demographics and their 
work setting/environment. Section 2 asked physiotherapists to indicate the conditions they currently treat and to rank the five conditions they most frequently treat using a Likert scale of 1 to 5 , where 1 was the most frequent and 5 the least frequent. Section 3 concentrated on physiotherapists' use and referrals of CAM as well as their opinions on effectiveness of these modalities. Physiotherapists were asked if CAM was available in their clinic, whether they practiced CAM, and the form(s) of CAM to which they refer patients and their reasons for doing this. They were then asked to rank the effectiveness of a range of CAM therapies for managing the five conditions they cited in Section B as treating most frequently as either "highly effective", "somewhat effective", "not effective", or "unsure" The 18 CAM therapies provided in the questionnaire were selected after reviewing previous literature (Hughes et al., 2011; Poynton et al., 2006; Quinn, 2006), consultation with the Ngāi Tahu Research Consultation Committee at University of Otago, and from the list of the National Center for Complementary and Alternative Medicine in the United States (National Center for Complementary and Alternative Medicine, 2000). These therapies were acupuncture, the Alexander technique, aromatherapy, chiropractic, faith/spiritual healing, herbal medicine, homeopathy, hypnotherapy, massage, meditation, osteopathy, Reiki, reflexology, shiatsu, qigong/tai chi, vitamins/ minerals, yoga, and mirimiri/romiromi. Physiotherapists were asked whether they were aware if their patients attended CAM therapists and if they routinely asked this question during an assessment.

Physiotherapists were then asked to state factors which they believed influenced the success of CAM as a treatment and the percentage of the effectiveness of CAM due to a placebo effect (i.e. non-specific effect). Physiotherapists were also asked whether CAM has a role in district health boards (DHBs). The final open question gave physiotherapists the opportunity to add a further comment regarding CAM and its use in New Zealand.

\section{Data analysis}

Data from completed surveys were exported from Qualtrics ${ }^{\circledR}$ as comma separated values into Microsoft Excel® where these were analysed. Data were checked for errors, and descriptive statistics were calculated. Response rate (number of respondents/number invited) and completion rate (number of respondents who completed the whole survey/number of respondents) were calculated. Three key cross tabulations were then completed to further analyse the data, including years of practice in relation to use of CAM, perceived effectiveness of a range of CAM modalities in relation to the most commonly treated condition, and estimation of a placebo effect of CAM in relation to use of CAM. The open-ended question was analysed using an inductive content analysis (Hsieh \& Shannon, 2005).

\section{RESULTS}

The study invitation and questionnaire were sent by email without practical problems. A response rate of $10.5 \%(n=$ 36/344) was obtained after the reminder was sent out. Five questionnaires were incomplete and, therefore, not included in the analysis, thus resulting in a completion rate of $86.1 \%(n=$ 31/36).
The mean age of respondents was 42.1 years with ages ranging from 24 to 62 years. The majority of respondents were female ( $n=19,61.3 \%)$. The largest ethnicity group was New Zealand European ( $n=24,77.4 \%)$, followed by Māori $(n=3,9.7 \%)$, "other" ( $n=3,9.7 \%)$. Eight respondents (25.8\%) had an undergraduate degree in physiotherapy and 23 (74.2\%) had completed postgraduate training, including a $\operatorname{PhD}(n=6$, $19.4 \%)$, master's degree $(n=4,12.9 \%)$, postgraduate diploma ( $n=10,32.3 \%)$, and postgraduate certificate $(n=3,9.7 \%)$. The mean time of practice was 18.9 years (ranged from 2 to 41 years). In terms of practicing clinic mode, 13 (41.9\%) worked in sole physiotherapy practices and 12 (38.7\%) worked in a multidisciplinary environment, which provided services including (but not limited to) physiotherapy, chiropractic, acupuncture, osteopathy, and massage. Of the respondents, 20 (64.5\%) worked in private practices, while seven $(22.6 \%)$ worked at the University of Otago and four (12.9\%) at the Southern District Health Board. There were 20 respondents (64.5\%) who worked in full-time employment. On average, the respondents treated 29.2 patients per week (ranged from 10 to 80 patients), with each patient treated for an average of 39 minutes/session (ranged from 25 to 60 minutes).

The conditions most frequently treated by respondents were "back and neck pain" ( $n=10)$ followed by "musculoskeletal upper limb injury" $(n=4)$, "neurological conditions" $(n=3)$, "sports injuries" $(n=3)$, "sprains and strains" $(n=2)$, and "other" $(n=4)$, including "falls and fractures", "cardiorespiratory physiotherapy", and "paediatrics" (Figure 1).

\section{Figure 1}

\section{Conditions Treated by Respondents}

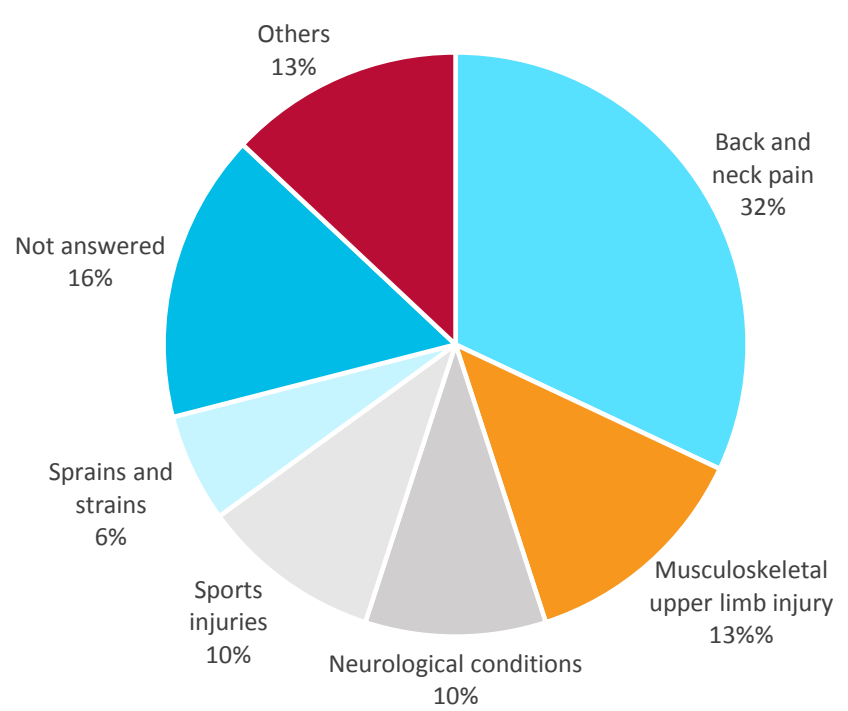

Just over half of respondents $(n=17 / 31)$ stated that a CAM service was available in their clinic. Slightly less than half of respondents ( $n=14 / 31$ ) reported that they practice some form of CAM: the most common form was acupuncture $(n=8 / 14)$. Other CAM therapies less commonly used by respondents included Reiki, bioptron light therapy, heat, cupping, and herbal remedies. Nearly half of respondents $(n=15 / 31)$ referred their patients to CAM practitioners, the most popular referral being 
an acupuncturist ( $n=7 / 15$ ). When asked about reasons for a CAM referral, the most common reason was "to supplement a conventional medical treatment".

The CAM treatments used for managing "back and neck pain" that were given the highest ratings for effectiveness (marked as "highly effective" or "somewhat effective") were acupuncture $(n=9)$, massage $(n=9)$, yoga $(n=6)$, meditation $(n=5)$, and osteopathy $(n=5)$ (Table 2). There were 22 respondents (71\%) who were aware of patients' use of a CAM therapist for treating their conditions, and almost all these respondents $(n=$ $21 / 22,95.6 \%$ ) reported that they routinely asked this question during patient assessments. Results of the cross tabulation between "years of practice" and "use of CAM" suggested that respondents with over 30 years of practice are proportionally more likely to be practicing a CAM (Figure 2).

Over three-quarters of respondents $(n=24 / 31)$ identified factors which they believe influenced the success of CAM, with 16/24 (66.7\%) stating "patients' opinions and/or beliefs towards CAM" to be the most common factor. Just over half of respondents ( $n=16 / 31$ ) considered that at least $50 \%$ of the effectiveness of CAM was due to a placebo effect. Interestingly, respondents who did not use CAM believed the placebo effect of CAM modalities was higher (mean, 63\%) compared to those who practiced CAM (mean, $46.2 \%$ ).

Nearly two-thirds of respondents $(n=19 / 31)$ believed that CAM had a role in the New Zealand publicly funded health and disability services. Of these 19 respondents, 85\% $(n=16 / 19)$ added comments, including the place for CAM as an evidencebased practice alongside Western medicine $(n=4)$, the need to give patients choice of treatment based on their beliefs and in

\section{Figure 2}

Years Practicing as a Physiotherapist and Use of CAM

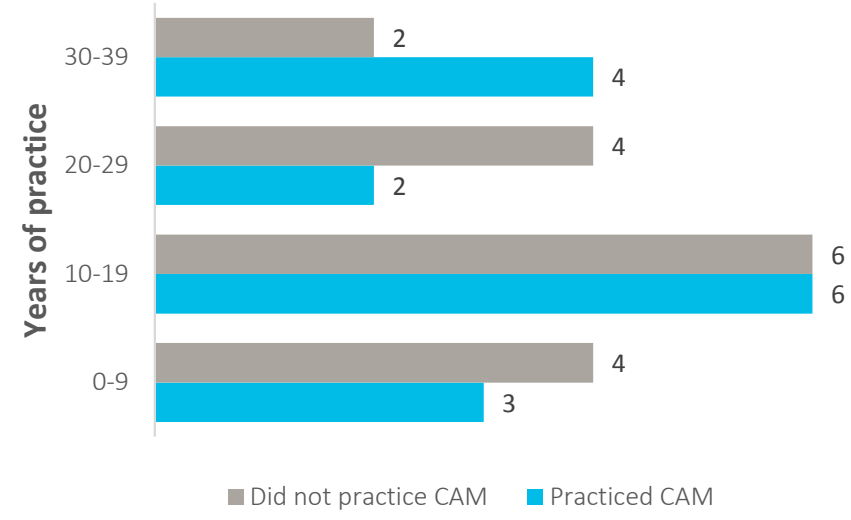

additional to physiotherapists' preferred conventional treatments $(n=4)$, and the endorsement of CAM in the New Zealand health system as long as it is practiced safely $(n=2)$.

Nine respondents added further comments regarding CAM and its use in New Zealand. These comments varied widely, and there were no obvious themes (Appendix B). Comments included "more training needed for undergraduate health care students to improve knowledge/awareness of CAM practices and to encourage safe practice", "replication of evidence in support of CAM therapies by independent groups is necessary to overcome the level of skepticism CAM has earned itself through a history of few, limited, and poorly conducted studies with high risk of bias", and "overcoming people's unwillingness

Table 2

Perceived Effectiveness of CAM Modalities for Treating Back and Neck Pain

\begin{tabular}{|c|c|c|c|c|c|}
\hline CAM modality & Highly effective & Somewhat effective & Not effective & Unsure & Not answered \\
\hline Acupuncture & 3 & 6 & 1 & 0 & 0 \\
\hline Alexander technique & 0 & 1 & 0 & 8 & 1 \\
\hline Aromatherapy & 0 & 0 & 4 & 5 & 1 \\
\hline Chiropractic & 0 & 4 & 2 & 3 & 1 \\
\hline Faith/spiritual healing & 0 & 0 & 4 & 5 & 1 \\
\hline Herbal medicine & 0 & 1 & 4 & 4 & 1 \\
\hline Homeopathy & 0 & 0 & 4 & 5 & 1 \\
\hline Hypnotherapy & 0 & 0 & 4 & 5 & 1 \\
\hline Massage & 2 & 7 & 0 & 0 & 1 \\
\hline Meditation & 3 & 2 & 3 & 1 & 1 \\
\hline Mirimiri/romiromi & 0 & 0 & 2 & 7 & 1 \\
\hline Osteopathy & 1 & 4 & 1 & 3 & 1 \\
\hline Qigong/tai chi & 0 & 4 & 3 & 2 & 1 \\
\hline Reflexology & 0 & 1 & 4 & 4 & 1 \\
\hline Reiki & 0 & 2 & 2 & 5 & 1 \\
\hline Shiatsu/acupressure & 0 & 3 & 1 & 5 & 1 \\
\hline Vitamin/minerals & 0 & 1 & 4 & 4 & 1 \\
\hline Yoga & 1 & 5 & 2 & 1 & 1 \\
\hline Other & 0 & 0 & 2 & 1 & 7 \\
\hline
\end{tabular}


to pay for treatment or nutritionals themselves is a major factor". Finally, one respondent added a comment regarding the design of questionnaire: "This questionnaire was difficult to answer for the population I work with, which is in a long-term rehab type setting".

\section{DISCUSSION}

This pilot survey of members of the Otago Branch of PNZ was the first study investigating the current practice and attitudes of New Zealand physiotherapists towards CAM in routine practice. It demonstrated that it is feasible to conduct a nationwide survey but with the aim of improving the survey design and response rate.

We achieved a response rate of $10.5 \%(n=36 / 344)$, which was lower compared to the rates in other similar survey studies (Harris et al., 2006; Hughes et al., 2011). Due to the limited timeframe of this study (this study was based on a 6-week research paper for final-year physiotherapy students), the survey was only active for 13 days, therefore the invited physiotherapists did not have long to respond. For the subsequent nationwide survey, a longer timeframe will be needed. Furthermore, a combination of techniques will be used to improve the response rate, including both postal and email contact, increased follow-ups, cash incentives, and different survey modes delivered in sequence (i.e., email then postal) (Millar \& Dillman, 2011). In addition, it may be worthwhile to conduct the survey onsite at physiotherapy professional assemblies, such as the PNZ national physiotherapy conference.

The completion rate of the survey was considered good at $86.1 \%(n=31 / 36)$. Overall, the response to the survey design was positive. One respondent suggested that future surveys be tailored for different areas of physiotherapy practice to canvas a wider group of respondents.

While findings from this pilot survey are limited by its small sample size and low response rate, there were several important preliminary findings from this study. Firstly, the most frequently treated condition by respondents was "back and neck pain", and the CAM modalities rated the most effective for treating this condition were acupuncture and massage (with the majority of respondents rating these two forms "somewhat" or "highly effective"). Secondly, acupuncture was the most popular CAM modality which respondents integrated into their practice, and an acupuncturist was the CAM practitioner to which patients were most commonly referred by respondents.

It is not surprising that "back and neck pain" was the most frequently treated condition in this study, given the high prevalence of back pain (Buchbinder et al., 2018; Hoy et al., 2012). It was reported that $40-60 \%$ of physiotherapists' patient load comprised low back pain (LBP), with the majority of patients being treated for chronic LBP (Hughes et al., 2011; Kolt \& McEvoy, 2003). Physiotherapists who responded to the survey rated acupuncture and massage as the most effective forms of CAM for managing back and neck pain. This was consistent with findings from a previous survey study conducted in the United Kingdom that reported physiotherapists believe acupuncture and massage were effective for relieving all types of LBP (Hughes et al., 2011). While physiotherapists may favour acupuncture and massage based on opinion or clinical experience, the accumulating evidence on the effectiveness of acupuncture and massage in the management of back and neck pain may also explain why they are preferred treatment options (Furlan et al., 2015; Liu et al., 2015).

This study found that acupuncture is the most popular form of CAM practiced by physiotherapists, and an acupuncturist is the CAM practitioner that physiotherapists mostly commonly refer their patients to. The number of physiotherapists practicing acupuncture in this study (57.1\%) was higher than the number of GPs (10\%) in New Zealand who incorporated acupuncture into their routine practice (Poynton et al., 2006). Apart from the established effectiveness of acupuncture (stated above), regulatory policy may also drive the popularity of acupuncture in New Zealand. New Zealand physiotherapists are recorded as having practiced acupuncture as early as 1972 (Scrymgeour, 2000) and acupuncture is considered within the general scope of physiotherapy practice by the regulatory body (Physiotherapy Board of New Zealand, 2004). Additionally, PNZ's Physiotherapy Acupuncture Association of New Zealand (PAANZ) special interest group provides ongoing training and peer support for physiotherapists using acupuncture, and regularly publishes guidelines for safe acupuncture and dry needling practice (Physiotherapy Acupuncture Association of New Zealand, 2018). Previous studies report that acupuncture courses are frequently attended by physiotherapists in the United Kingdom (Foster et al., 1999; Gracey et al., 2002). In New Zealand, although such data are not available, acupuncture training (for physiotherapists) is provided at a postgraduate level in public tertiary education organisations.

From this limited sample of survey respondents, there was no correlation between "years of practicing" and "use of CAM"; firm conclusions cannot be reached without a further nationwide survey with a higher response rate. Interestingly, this study found that there was a clear trend toward physiotherapists who do not practice CAM believing that the success of CAM was more likely attributable to a placebo effect (non-specific effect). While there has been ongoing debate around the non-specific effects of CAM (as well as conventional therapy), CAM therapists view the placebo effect as patient's self-healing power, resulting from the establishment of a patient's trust and belief during the treatment process (Stub et al., 2017). This may challenge an orthodox medical system that supports the use of intervention/medicine if it results from the application of biomedical concepts and science. Nevertheless, CAM is apparently perceived by many patients as aligned with their general philosophy and ideas regarding illness and health care, and provides patients more control over their condition and relevant treatments (Corp et al., 2018). In this study, over three-quarters of respondents identified factors which they believed influenced the success of CAM, with the overwhelming theme being "patients' opinion or beliefs on CAM". This was in keeping with a previous study which identified an individual's confidence in CAM treatments or practitioners was, in some cases, simply expressed as trusting, having faith, or believing in a particular CAM therapy (Corp et al., 2018). Nevertheless, more research is needed before these conclusions can be drawn. 
Despite the response rate limitations, this study found that $71 \%$ of physiotherapists were aware that their patients attended CAM practitioners, and the majority of respondents routinely asked this during their assessment. This is at odds with findings from previous studies which reported that up to $77 \%$ of patients using CAM do not tell their medical practitioners (Robinson \& McGrail, 2004; Thomson et al., 2012). Reasons cited for such behaviour included "concerns about a negative response by the practitioners, the belief that the practitioner did not need to know about their CAM use, and the fact that the practitioner did not ask" (Robinson \& McGrail, 2004). The current study indicated that for this sample of physiotherapists at least, the physiotherapist-patient communication around CAM use is more open, although the openness of communication was not specifically assessed in this study. An earlier study reviewed physicians' attitudes and practices regarding CAM, as physicians have a major role in controlling patients' beliefs and attitudes towards CAM (Milden \& Stokols, 2004). It found that $61 \%$ of physicians discouraged CAM use simply due to lack of knowledge and insight on CAM's safety and efficacy, but $81 \%$ showed an interest in gaining more CAM knowledge, and providing sufficient clinical trials, education and resources to support CAM practice. The latter finding was consistent with an earlier New Zealand survey of GPs which suggested that appropriate education about CAM should be included in the medical curriculum and that CAM therapies need more scientific testing before being used in conventional medicine (Poynton et al., 2006).

As a pilot survey, the primary limitation of this study was the small sample size and low response rate. However, this also reflected the purpose of a pilot study, which is to test the rationale and method proposed for use in the main study (Arain et al., 2010). Due to a large percentage of respondents with a postgraduate qualification (74.2\%), the survey results may not accurately represent the practices and attitudes of all physiotherapists in New Zealand, as the data is likely to be skewed towards an academic perspective. In order to capture a comprehensive understanding of New Zealand physiotherapists' current practice and attitudes towards CAM, a nationwide survey with New Zealand registered physiotherapists based on recommendations from this pilot survey represents the next phase of investigation. The nationwide survey is planned for 2021. Based upon the current number of registered physiotherapists in New Zealand $(n=5,417)$ (Physiotherapy Board of New Zealand, 2020), an estimated sample size of 350 will allow a confidence level of $95 \%$ with a margin of error of $5 \%$ for such a survey, although as already noted, more efforts are needed to improve the response rate and survey design.

\section{CONCLUSION}

This pilot study investigated the current practice and attitudes of physiotherapists in the Otago region of New Zealand. It found that the most frequently treated conditions by participating physiotherapists were "back and neck pain", and acupuncture and massage were rated as the most effective CAM modalities in treating these two conditions. The most common form of CAM used by physiotherapists was acupuncture, and an acupuncturist was the CAM practitioner that physiotherapists most commonly referred patients to. The study demonstrated that it is feasible to conduct a nationwide survey, subject to an improved survey design and response rate. Such a survey is scheduled in 2021, which will gather a more representative understanding of the practice and attitudes towards CAM among New Zealand physiotherapists.

\section{KEY POINTS}

1. Acupuncture and massage were the most effective CAM modalities for treating "back and neck pain".

2. The most common CAM modality used by respondents was acupuncture.

3. The most common referral to a CAM practitioner by respondents was an acupuncturist.

4. Recommendations from this pilot survey will help improve the response rate and design of a nationwide survey investigating the current practice and attitudes towards CAM among New Zealand registered physiotherapists.

\section{DISCLOSURES}

No funding was obtained for this study. There are no conflicts of interest which may be perceived to interfere with or bias this study.

\section{PERMISSIONS}

Ethical approval was obtained from the University of Otago Human Ethics Committee (Health) (reference number 18/117).

\section{ACKNOWLEDGEMENTS}

The authors thank David Jackson for his assistance with the survey setup in Qualtrics.

\section{ADDRESS FOR CORRESPONDENCE}

Dr Lizhou Liu, Centre for Health, Activity and Rehabilitation Research, School of Physiotherapy, University of Otago, PO Box 56, Dunedin, New Zealand

Email: lizhou.liu@otago.ac.nz

\section{REFERENCES}

Abuelgasim, K. A., Alsharhan, Y., Alenzi, T., Alhazzani, A., Ali, Y. Z., \& Jazieh, A. R. (2018). The use of complementary and alternative medicine by patients with cancer: A cross-sectional survey in Saudi Arabia. BMC Complementary and Alternative Medicine, 18(1), 88. https://doi. org/10.1186/s12906-018-2150-8

Adams, J., Andrews, G., \& Barnes, J. (2012). Traditional, complementary and integrative medicine: An international reader. Palgrave Macmillian.

Arain, M., Campbell, M. J., Cooper, C. L., \& Lancaster, G. A. (2010). What is a pilot or feasibility study? A review of current practice and editorial policy. BMC Medical Research Methodology, 10, 67. https://doi. org/10.1186/1471-2288-10-67

Asfaw Erku, D., \& Basazn Mekuria, A. (2016). Prevalence and correlates of complementary and alternative medicine use among hypertensive patients in Gondar Town, Ethiopia. Evidence-Based Complementary and Alternative Medicine, 2016, 6987636. https://doi.org/10.1155/2016/6987636

Buchbinder, R., van Tulder, M., Öberg, B., Costa, L. M., Woolf, A., Schoene, M., \& Croft, P; on behalf of the Lancet Low Back Pain Series Working Group. (2018). Low back pain: A call for action. Lancet, 391(10137), 2384-2388. https://doi.org/10.1016/s0140-6736(18)30488-4 
Chrystal, K., Allan, S., Forgeson, G., \& Isaacs, R. (2003). The use of complementary/alternative medicine by cancer patients in a New Zealand regional cancer treatment centre. New Zealand Medical Journal, 116(1168), U296.

Corp, N., Jordan, J. L., \& Croft, P. R. (2018). Justifications for using complementary and alternative medicine reported by persons with musculoskeletal conditions: A narrative literature synthesis. PLoS One, 13(7), e0200879. https://doi.org/10.1371/journal.pone.0200879

Dew, K. (2003). Borderland practices: Regulating alternative therapies in New Zealand. University of Otago Press.

Foster, N. E., Thompson, K. A., Baxter, G. D., \& Allen, J. M. (1999). Management of nonspecific low back pain by physiotherapists in Britain and Ireland. A descriptive questionnaire of current clinical practice. Spine 24(13), 1332-1342. https://doi.org/10.1097/00007632-199907010-00011

Frass, M., Strassl, R. P., Friehs, H., Mullner, M., Kundi, M., \& Kaye, A. D. (2012). Use and acceptance of complementary and alternative medicine among the general population and medical personnel: A systematic review. The Ochsner Journal, 12(1), 45-56

Furlan, A. D., Giraldo, M., Baskwill, A., Irvin, E., \& Imamura, M. (2015). Massage for low-back pain. Cochrane Database of Systematic Reviews, (9), CD001929. https://doi.org/10.1002/14651858.CD001929.pub3

Gracey, J. H., McDonough, S. M., \& Baxter, G. D. (2002). Physiotherapy management of low back pain: A survey of current practice in northern Ireland. Spine 27(4), 406-411. https://doi.org/10.1097/00007632200202150-00017

Harris, I. M., Kingston, R. L., Rodriguez, R., \& Choudary, V. (2006). Attitudes towards complementary and alternative medicine among pharmacy faculty and students. American Journal of Pharmaceutical Education 70(6), 129. https://experts.umn.edu/en/publications/attitudes-towardscomplementary-and-alternative-medicine-among-ph

Hoy, D., Bain, C., Williams, G., March, L., Brooks, P., Blyth, F., Woolf, A., Vos, T., \& Buchbinder, R. (2012). A systematic review of the global prevalence of low back pain. Arthritis \& Rheumatology, 64(6), 2028-2037. https://doi. org/10.1002/art.34347

Hsieh, H. F., \& Shannon, S. E. (2005). Three approaches to qualitative content analysis. Qualitative Health Research, 15(9), 1277-1288. https://doi. org/10.1177/1049732305276687

Hughes, C. M., Quinn, F., \& Baxter, G. D. (2011). Complementary and alternative medicine: Perception and use by physiotherapists in the management of low back pain. Complementary Therapies in Medicine, 19(3), 149-154. https://doi.org/https://doi.org/10.1016/j.ctim.2011.03.003

Kolt, G. S., \& McEvoy, J. F. (2003). Adherence to rehabilitation in patients with low back pain. Manual Therapy, 8(2), 110-116. https://doi. org/10.1016/s1356-689x(02)00156-x

Leach, M. (2010). Clinical decision making in complementary \& alternative medicine (1st ed.). Churchill Livingstone.

Liu, L., Skinner, M., McDonough, S., Mabire, L., \& Baxter, G. D. (2015). Acupuncture for low back pain: An overview of systematic reviews. Evidence-Based Complementary and Alternative Medicine, 2015, 328196. https://doi.org/10.1155/2015/328196

Milden, S. P., \& Stokols, D. (2004). Physicians' attitudes and practices regarding complementary and alternative medicine. Behavioral Medicine 30(2), 73-82. https://doi.org/10.3200/bmed.30.2.73-84

Millar, M. M., \& Dillman, D. A. (2011). Improving response to web and mixed-mode surveys. Public Opinion Quarterly, 75(2), 249-269. https://doi. org/10.1093/poq/nfr003

Ministry of Health. (2004). A portrait of health: Key results of the 2002/03 New Zealand Health Survey. https://www.moh.govt.nz/notebook/nbbooks. nsf/0/1A291BC68D950D60CC25770D007208AE/\$file/aportraitofhealth. pdf

National Center for Complementary and Alternative Medicine. (2000). Expanding horizons of healthcare: Five-year strategic plan 2001-2005 National Institute of Health Publication. https://files.nccih.nih.gov/s3fspublic/about/plans/2005/strategicplan.pdf
Nicholson, T. (2006). Complementary and alternative medicines (including traditional Māori treatments) used by presenters to an emergency department in New Zealand: A survey of prevalence and toxicity. New Zealand Medical Journal, 119(1233), U1954.

Osborn, C. (2001). Complementary and alternative medicine and the treatment of rheumatic diseases: Focusing on aromatherapy [unpublished doctoral thesis]. Coventry University.

Physiotherapy Acupuncture Association of New Zealand. (2009). A brief history of PAANZ. Retrieved December 10, 2018, from http://www.paanz. org.nz/webpage.php?id=98

Physiotherapy Board of New Zealand. (2004, December). Acupuncture. A modality within the practice of physiotherapy. InTouch. The Newsletter of the Physiotherapy Board of New Zealand.

Physiotherapy Board of New Zealand. (2008). The scopes of physiotherapy. Retrieved January 21, 2020, from https://www.physioboard.org.nz/i-amregistered/scopes-of-practice

Physiotherapy Board of New Zealand. (2020). Search register. Retrieved August 20, 2020, from https://www.physioboard.org.nz/search-register

Physiotherapy New Zealand. (2018). Annual report. https://pnz.org.nz/ annual-reports

Pledger, M. J., Cumming, J. N., \& Burnette, M. (2010). Health service use amongst users of complementary and alternative medicine. New Zealand Medical Journal, 123(1312), 26-35. https://pubmed.ncbi.nlm.nih. gov/20389315/

Poynton, L., Dowell, A., Dew, K., \& Egan, T. (2006). General practitioners' attitudes toward (and use of) complementary and alternative medicine: A New Zealand nationwide survey. New Zealand Medical Journal, 119(1247), U2361

Quinn, F. (2006). Complementary and alternative medicine in the treatment of low back pain, with a focus on reflexology [unpublished doctoral thesis]. University of Ulster.

Robinson, A., \& McGrail, M. R. (2004). Disclosure of CAM use to medical practitioners: A review of qualitative and quantitative studies. Complementary Therapies in Medicine, 12(2-3), 90-98. https://doi.org/10.1016/j.ctim.2004.09.006

Scrymgeour, J. (2000). Moving on: A history of the New Zealand Society of Physiotherapists Inc., 1973-1999. New Zealand Society of Physiotherapists.

Stratton, T. D., \& McGivern-Snofsky, J. L. (2008). Toward a sociological understanding of complementary and alternative medicine use. Journal of Alternative and Complementary Medicine, 14(6), 777-783. https://doi. org/10.1089/acm.2007.7006

Stub, T., Foss, N., \& Liodden, I. (2017). "Placebo effect is probably what we refer to as patient healing power": A qualitative pilot study examining how Norwegian complementary therapists reflect on their practice. BMC Complementary and Alternative Medicine, 17, 262. https://doi. org/10.1186/s12906-017-1770-8

Teo, T. Y., Yap, J., Shen, T., \& Yeo, K. K. (2016). Complementary and alternative medicine use amongst patients with cardiovascular disease in Singapore. BMC Complementary and Alternative Medicine, 16, 446 https://doi.org/10.1186/s12906-016-1430-4

Thomson, P., Jones, J., Evans, J. M., \& Leslie, S. L. (2012). Factors influencing the use of complementary and alternative medicine and whether patients inform their primary care physician. Complementary Therapies in Medicine, 20(1-2), 45-53. https://doi.org/10.1016/j.ctim.2011.10.001

Wode, K., Henriksson, R., Sharp, L., Stoltenberg, A., \& Hök Nordberg, J. (2019). Cancer patients' use of complementary and alternative medicine in Sweden: A cross-sectional study. BMC Complementary and Alternative Medicine, 19, 62. https://doi.org/10.1186/s12906-019-2452-5 


\section{APPENDIX A}

COMPLEMENTARY AND ALTERNATIVE MEDICINE: A SURVEY OF CURRENT CLINICAL PRACTICE AND ATTITUDES OF PHYSIOTHERAPISTS

\section{Demographic information}

Reference number:

Gender: $\square \quad$ Male $\square \quad$ Female $\square$

Age: years

Ethnicity:

$\square$ New Zealand European
$\square$ Nivean $\quad \square$ Samoan
$\square$ Indian $\quad \square$ Other:

$\square$ Māori $\quad \square$ Cook Island Māori

Tongan $\square$ Chinese

Education qualification in physiotherapy (tick more than one item if applicable):

$\square$ BPhty $\square$ BPhty(Hons) $\square$ PGCertPhty $\quad \square$ PGDipPhty
$\square$ MPhty $\square$ PhD $\square$ Other (please state):

Year(s) you gained your qualification:

Training place(s):

Total length of training: years

New Zealand registered physiotherapist (general scope of practice): $\square$ Yes $\square$ No

Currently practicing: $\square$ Yes $\square$ No

Years of practice: _ years

Employment status: $\quad \square$ Full-time $\quad \square$ Part-time

Practicing clinic address:

Practicing clinic mode: $\square$ sole physiotherapy $\quad \square$ Multidisciplinary rehabilitation

Numbers of patients you treat per week:

Average length of treatment per patient: $\min$ 


\section{General clinical practice}

From the list below, please tick the following conditions that you have treated/are treating in your current clinical practice (tick all that apply). In addition, please rank 5 conditions you most frequently treat in the order of 1 to 5 where 1 is the most frequent.

\begin{tabular}{|c|c|c|c|c|c|}
\hline Condition & Tick box & Ranking & Condition & Tick bo & Ranking \\
\hline Arthritis & & & Post-surgery & $\square$ & \\
\hline Carpal tunnel syndrome & & & Repetitive strain & $\square$ & \\
\hline Chronic pain syndrome & & & Rotator cuff injury & L & \\
\hline Concussion & 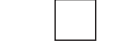 & & Running injuries & $\square$ & \\
\hline Dizziness, vertigo, and imbalance & & & Sciatica & $\square$ & \\
\hline Frozen shoulder & & & Sports injuries & $\square$ & \\
\hline Golfer's elbow & & & Sprains and strains & $\square$ & \\
\hline Headaches & & & Tendonitis & $\square$ & \\
\hline Heel and foot pain & & & Tennis elbow & $\square$ & \\
\hline Low back pain & & & Temporomandibular joint dysfunction & $\square$ & \\
\hline Motor vehicle accident injuries & $\square$ & & Whiplash & $\square$ & \\
\hline Paediatric conditions & $\square$ & & Other (please state) & $\square$ & \\
\hline Pelvic floor conditions & & & & & \\
\hline
\end{tabular}

\section{Complementary and alternative medicine (CAM)}

1. Is any form of CAM service available in your clinic or department (see list over page)?

$\square$ No

$\square$ Yes (please state):

2. Do you practice any forms of CAM?

$\square$ No

Yes (please state):

3. Do you refer patients to CAM practitioners?

$\square$ No

$\square$ Yes (please state forms of CAM and the associated conditions for which you refer patients):

CAM Conditions

4. What is the reason you refer patients to use CAM?
$\square$ To treat a specific condition
$\square$ To supplement a conventional medical treatment
$\square$ Relaxation
Advised by colleague
$\square$ Advised by research findings
Other (please state):

5. In your opinion, how effective are the following CAM treatments in managing patients' symptoms? Please first write the names of the 5 conditions you most frequently treat in row 2, and then state the effectiveness level of the CAM treatments for each of these 5 conditions: 
( 1 = highly effective; 2 = somewhat effective; 3 = not effective; 0 = unsure)

\begin{tabular}{|c|c|c|c|c|c|}
\hline \multirow{2}{*}{ CAM } & \multicolumn{5}{|c|}{ Name of condition } \\
\hline & Condition 1 & Condition 2 & Condition 3 & Condition 4 & Condition 5 \\
\hline \multicolumn{6}{|l|}{ Acupuncture } \\
\hline \multicolumn{6}{|l|}{ Alexander technique } \\
\hline \multicolumn{6}{|l|}{ Aromatherapy } \\
\hline \multicolumn{6}{|l|}{ Chiropractic } \\
\hline \multicolumn{6}{|l|}{ Faith/spiritual healing } \\
\hline \multicolumn{6}{|l|}{ Herbal medicine } \\
\hline \multicolumn{6}{|l|}{ Homeopathy } \\
\hline \multicolumn{6}{|l|}{ Hypnotherapy } \\
\hline \multicolumn{6}{|l|}{ Massage } \\
\hline \multicolumn{6}{|l|}{ Meditation } \\
\hline \multicolumn{6}{|l|}{ Osteopathy } \\
\hline \multicolumn{6}{|l|}{ Reiki } \\
\hline \multicolumn{6}{|l|}{ Reflexology } \\
\hline \multicolumn{6}{|l|}{ Shiatsu } \\
\hline \multicolumn{6}{|l|}{ Qigong/tai chi } \\
\hline \multicolumn{6}{|l|}{ Vitamins/minerals } \\
\hline \multicolumn{6}{|l|}{ Yoga } \\
\hline \multicolumn{6}{|l|}{ Mirimiri or romiromia } \\
\hline Other (please state) & & & & & \\
\hline
\end{tabular}

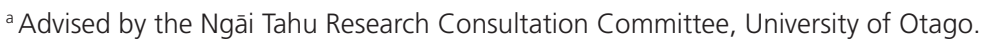

6. (i) Are you aware whether patients you treat also use CAM for their conditions?

$\square$ Yes $\square$ No $\square$ Unsure

(ii) If yes, do you routinely ask this question during assessment?

$\square$ Yes $\square$ No

7. Can you identify factors that in your opinion or experience influence the success of CAM?

8. Part of the effectiveness of any medical treatment, whether a CAM or conventional treatment, is due to a placebo effect. What percentage of the effectiveness of CAM do you believe is due to a placebo effect?

9. Do you believe CAM has a role in the New Zealand publicly funded health and disability services?

$\square$ No

$\square$ Yes (please state):

10. If you have any further comments regarding CAM and its use in New Zealand, please state below.

Thank you for taking time to complete this survey. Your help with this research is much appreciated. 


\section{Appendix B}

\section{RESPONDENTS' COMMENTS ON CAM AND ITS USE IN NEW ZEALAND}

\section{Quotes $^{\mathrm{a}}$}

Replication of evidence in support of CAM therapies by independent groups is necessary to overcome the level of skepticism CAM has earned itself through a history of few, limited, and poorly conducted studies with high risk of bias. (1/M/NK)

My feelings can be summed up by something I saw on Facebook. Alternative medicine that works is called medicine. Basically, once it has been investigated and proven to work, it's no longer alternative rather it becomes medicine. (2/M/36)

More training needed for undergraduate health care students (medical/allied health/nurses/dental etc.) to improve knowledge/ awareness of CAM practices and to encourage safe practice. Joint research projects would be great to review effectiveness of CAM practices and also of placebo in general. (4/F/40)

CAM can be a useful adjunct to allow comfort to push exercise therapy if patient keen to complete both. In our population, patients often fund naturopathy, massage therapy or acupuncture as part of their treatment plan. This is their decision, and I do not influence their decision to complete these as part of their overall treatment plan. (7/F/39)

Wouldn't have classified chiropractic and osteopathy as CAM. (8/F/50)

Overcoming people's unwillingness to pay for treatment or nutritionals themselves is a major factor. (11/F/62)

There are many components of my "physiotherapy" practice, and that of colleagues, which have borrowed from insights and experience of CAM - aspects of meditation, visualisation, diet, movement therapies, including Alexander technique, yoga and tai chi, because these offer modes of practicing holistically - recognising there is little success in treating the hole in the patient; you have to treat the whole patient/person. (18/NK/42)

This questionnaire was difficult to answer for the population I work with, which is in a long- term rehab type setting. I wonder if having different surveys for different settings might improve the accuracy/specificity of your information. (23/F/36)

Based on the evidence, we can use some CAM therapies as part of comprehensive integrated care. (26/M/60)

Note. $\mathrm{CAM}=$ complementary and alternative medicine; $\mathrm{F}=$ female; $\mathrm{M}=$ male; $\mathrm{NK}=$ not known.

a Quotes were identified by study number, sex, and age. 